\title{
A Cephalometric Comparative Study for Upper Airway Dimensions in Different Craniofacial Growth Patterns
}

AIM AND OBJECTIVES: To compare different craniofacial patterns with pharyngeal widths. In OSA (Obstructive Sleep Apnea) patients, a mutual association between the pharyngeal structures and the dentofacial patterns has been suggested. The present study was performed to compare the nasopharynx, oropharynx and hypopharynx dimensions of persons with hypodivergent, normodivegent and hyperdivergent facial types and to predict and to facilitate treatment for OSA patients.

Hypothesis: The Null hypothesis for the study was that there is no difference between the upper airway for patients with different growth pattern. MATERIALS AND METHOD: The sample comprised 6o patients divided into three groups: hypodivergent $(\mathrm{n}=20)$, normodivergent ( $\mathrm{n}=20)$, and hyperdivergent $(\mathrm{n}=20)$ according to Jarabak's ratio and FH-MP angle, which were used to compare the soft tissue airway dimensions. The statistical analysis was performed using Student's t-Test, one way ANOVA (analysis of variance) and LSD (Least significant difference) test. RESULT: Overall narrower anteroposterior pharyngeal dimension was found in the hyperdivergent group as compared to the normodivergent group. Whereas, the superior part of upper pharyngeal width in the subjects with hypodivergent growth pattern was significantly narrower than in normal growth pattern groups.

CONCLUSION: In hyperdivergent patients, the narrower anterioposterior dimension of the airway may be due to the skeletal features common to such patients, i.e., posterior vertical maxillary excess, posterior position and decreased mandibular size. The variations of the upper airway may be attributed to the horizontal and vertical growth patterns. Upper airway obstruction and later on OSA may be predisposed by skeletal deficiency.

KEYWORDS: Lateral cephalometry, Superior part of upper airway, Inferior part of upper airway, Craniofacial Patterns.

\section{INTRODUCTION}

For accurate orthodontic diagnosis and correct treatment planning, respiration function plays a key role. ${ }^{1}$ Various predisposing factors have been reported in the literature for obstruction of pharyngeal airways; some of these include allergies, environmental irritants and infections, it has been reported that narrower airway passages have a natural anatomical predisposition. ${ }^{2}$ A close association exists between the pharynx and dentofacial structures in obstructive sleep apnea (OSA) patients; ${ }^{3}$ it is expected that a mutual interaction occurs between pharyngeal structures and various dento-facial patterns.

In clinical orthodontics, traditional cephalometry is extensively used to quantify skeletal and soft-tissue dysplasia before the initiation of therapy. ${ }^{4}$ Cephalometry has many significant advantages like its easy access, minimal radiation exposure and low cost. Therefore, to assess the pharyngeal airway, lateral and frontal view have also been extensively used. ${ }^{5}$

This study was conducted to compare the dimensions of the nasopharynx, oropharynx and hypopharynx in persons with hypodivergent, normodivergent and hyperdivergent facial types and to predict and facilitate the treatment for OSA patients.

\section{MATERIAL AND METHODS}

This retrospective analytical study was conducted with the sample, taken from the Department of Orthodontics which comprised of pre-treatment Lateral cephalograms of 60 subjects of both genders, with age range of 11-16 years (mean age 13.8 years).

The main inclusion criteria were patients without any pharyngeal pathology and those without a history of any surgery related to palatine or pharyngeal tonsils (tonsillectomy or adenoidectomy). Patients having craniofacial syndromes were excluded.

Usual standardized lateral cephalograms were taken. The radiographs were exposed with patient's Frankfort horizontal (FH) plane parallel to the floor. While the radiographs were being exposed, the subjects were instructed neither to swallow nor to move their head and tongue and to lightly contact their teeth with relaxed lips.

Three groups with 20 subjects each were made, based on hypo-divergent, normo-divergent and 
hyper-divergent facial pattern. (Table 1)

On an acetate paper, the cephalometric tracings, landmarks identifications and measurements were performed by a single investigator. The pharyngeal structures were assessed using six skeletal and seven soft tissue parameters, (Figure 1, Table 2) based on the methods described by Lowe et al., ${ }^{6}$ Tangugsorn et al., ${ }^{7}$ Liu et al. ${ }^{8}$

Ten radiographs were randomly selected from the observation group in order to assess the errors associated with the radiographic measurements. 2 weeks after the first measurement, all the tracings and the measurements of these films were repeated. On applying a paired t-test, no error associated with the first and second measurements of radiographic tracings were found.

A variance analysis was used to study the effects of sex and age on the size of the pharynx, and no significant differences were detected. Ranges, means and standard deviations were computed for each measurement in the groups. The Student's t-Test, One way ANOVA (analysis of variance) and LSD (Least significant difference) test, was used for statistical analysis.

\section{RESULT}

The upper airway dimensions in horizontal growth pattern are comparatively less as with vertical growth pattern. The most statistically significant difference exists at the SPP-SPPW level in horizontal growth pattern. The most significant difference exists between PNS-R and V-LPW in vertical growth pattern.

In vertical growth pattern, superior and inferior upper airway dimension is decreased, whereas horizontal growth pattern, show more difference in the superior upper way, in comparison with the average growth pattern. No statistically significant difference was found between the vertical and the horizontal growth pattern, except at PNR-Ba level. (Table 3)

A statistically significant difference exists in mandibular size and positions in different growth patterns and results showed reduced mandibular dimensions in hyperdivergent growth patterns. Similarly, craniofacial complex dimensions are compared, and results showed a significant difference for hyperdivergent growth pattern. (Table 4)

\section{DISCUSSION}

During normal respiration, the nasal and pharyngeal structures are sufficiently used. ${ }^{9}$ To determine the mode of breathing, whether nasal or oral, the size of the nasopharynx is of great importance..$^{10}$ Therefore, it is suggested to exclude all the factors that affect the normal breathing and pharynx size, so that anterio-posterior relationship of the jaws can be correctly analyzed. Therefore, this study included children with normal breathing patterns only.

The ANB angle, which is most commonly used to determine the anterio-posterior dento-facial discrepancy, ${ }^{11}$ was excluded from the criteria for classifying the subjects as Ceylan and Oktayı2 demonstrated that the changes in the ANB angle do not affect the pharyngeal structures. Also, De Freitas et al.13 reported that type of malocclusion did not influence upper pharyngeal airway width.

The FH- MP angle has long been used to define the different types of growth patterns, ${ }^{14}$ but the use of FMA angle comes with the few drawbacks i.e. orientation during taking radiograph and reproducibility during tracing. Considering these pitfalls, Jarabak's ratio has also been considered with the FH-MP angle as the norms to classify growth patterns in this study.

More recently, researchers concluded that the nasopharyngeal depth is established until the age of 2 years and thereafter this dimension remains constant, ${ }^{15}$ however, when data is ranked according to biologic landmarks, pubertal growth spurts and sexual dimorphism in the growth patterns are consistently found.${ }^{16}$ Even though the growth of the pharynx has received considerable attention, the statement of the Scott ${ }^{17}$ that "less is known about the growth of the pharyngeal region than any other part of the face" is largely true. The sagittal measurements are stable because this study consisted of subjects from 11 to 16 years of age.

The fact that all the soft tissue pharyngeal parameters (PNS-R of the nasopharynx, PNS-Adı of orophaynx SPP-SPPW in middle of the palatepharynx and U-MPW to V-LPW level of the hypopharynx) showed significant difference among the hyperdivergent facial skeletal pattern, in this 
study. This may be due to various skeletal features which are common to such patients, i.e., posterior vertical maxillary excess, posterior position and decreased mandibular size. Hou et al.18 found that mandibular body length is a significant predictor for OSA and the mandibular size and position are corelated with pharyngeal dimensions. (Table 4)

The McNamara's airway analysis was used by Freitas et al. ${ }^{19}$ to compare the widths of upper and lower pharyngeal airway in individuals with untreated class I and class II malocclusions and normal and vertical growth patterns. It has been reported that upper pharyngeal dimensions in these patients are narrower than normal growth pattern group. In this study, with increases in Frankfort mandibular plane angle, the analysis of the S-N, ANS-PNS, and PNS-Ba decreased. (Table 4) The identical tendency may imply that the decrease in the upper airway dimensions in hyper-divergent patients was caused by the deficient development of the cranio-maxillary complex.

Zhong et al., ${ }^{20}$ suggests sagittal facial pattern as the possible explanation for the discrepancy in the depth of the superior part of the upper airway as a result of mandibular size and position. They also reported that variations in the superior part of the upper airway might be due to sagittal skeletal patterns. In this study, the superior part of upper pharyngeal width in individuals with hypodivergent growth pattern is significantly narrow than in the groups with normal growth pattern, in contrast to the study of Sarwat et al., ${ }^{21}$ who concluded that hypo-divergent pattern has no influence on the upper pharyngeal width.

As the FMA angle increase, the PNS-R dimensions decrease. In the vertical growth pattern, it shows a statistically significant reduction in dimension as compared with average growth pattern. There is a marked reduction in the dimension at PNS- Adı level (oropharynx) in horizontal growth pattern. The SPPSPPW dimension in horizontal and vertical growth pattern remains constant; that it is significantly reduced but doesn't get affected whether horizontal or vertical. The U-MPW level is affected by both horizontal and vertical growth pattern as compared with average growth pattern. (Figure 1)

At TB-TPPW level, dimensions get reduced in vertical as well as horizontal growth pattern. Also, a marked reduction is noted at V-LPW level in vertical growth pattern as compared with horizontal growth pattern.

Liu et al., ${ }^{22}$ demonstrated that significantly higher apnea index and respiratory disturbance index is found in OSA patients with more retrognathic mandibles and this results in various changes in the posture such as open mandible posture, the downward and forward positioning of tongue and extension of the head. Whenever, these postural changes continue for a longer period, especially during the active growth stage, dentofacial disorders of varying levels of severity can be seen, along with inadequate lip structure, long face syndrome and adenoid facies. ${ }^{23-26}$ The individuals at risk for OSA can be identified by early diagnosis of the skeletal pattern with a coexistent pharyngeal narrowing.

Since nasopharynx consists of complex $3 \mathrm{D}$ anatomic structures, the lateral cephalometric radiographs have limited use in the evaluation of the upper airway because they provide 2-D pictures. Though, Cameron et al. ${ }^{27}$ in their study found a significant positive relationship between computed tomography (CT) and cephalometric films, but, substantial volumetric change occurs with little change in linear measurement, and this could significantly affect the airway resistance. Since this was only an anatomic assessment, it partially demonstrated that an upper airway narrowing might be a predisposition to skeletal deficiency. In-order to further understand the airway status, it would be useful to conduct long-term prospective longitudinal studies which should consist of functional assessment measuring air flow.

\section{CONCLUSION}

- The horizontal and vertical growth patterns may contribute to the variations of the upper airway.

- In hyper-divergent patients, the narrower anterioposterior airway dimension may be due to various skeletal features which are common to such patients, i.e., posterior vertical maxillary excess, posterior position and decreased mandibular size.

- Skeletal deficiency may predispose them to upper airway obstruction and later to obstructive sleep apnea (OSA).

\section{REFERENCES}

1. Holmberg H, Linder Aronson S: Cephalometric radiographs as a means of evaluating the capacity of 
the nasal and nasopharyngeal airway. Am J Orthod,1979:76:479.

2. Cheng MC, Enlow DH, Papsidero M, Broadbent BH Jr, Oyen O, Sabat M. Developmental effects of impaired breathing in the face of the growing child. Angle Orthod 1988;58: 309-20.

3. Lowe AA, Santamatia JD, Fleetham JA, et al. Facial morphology and obstructive sleep apnoea. Am J Orthod Dentofacial Orthop. 1986;90: 484-91.

4. Burstone CJ, James RB, Legan H, Murphy GA, Norton LA. Cephalometrics for orthognathic surgery. J Oral Surg, 1978: 36: 269-77.

5. Brodie A. On the growth pattern of human head from the third month to the eighth year of life. Am J Anat 1941:68:209

6. Lowe AA, Ono T, Fleetham JA, et al. Cephalometric comparisons of craniofacial and upper airway structure by skeletal subtype and gender in patients with obstructive sleep apnea. Am J Orthod Dentofacial Orthop. 1996; 110: 653-64.

7. Tangugsorn V, Skatvedt O, Krogstad O, et al. Obstructive sleep apnea: a cephalometric study. Part II.uvulo - glossopharyngeal morphology. Eur J Orthod. 1995;17:57-67.

8. Liu Y, Zeng X, Lowe AA, et al. Effects of a mandibular repositioner on obstructive sleep apnea. Am J Orthod Dentofacial Orthop. 2000;118:248-56.

9. Subtelny JD. Oral respiration: facial maldevelopment and corrective dentofacial orthopedics. Angle Orthod 1980;50:147-64.

10. Linder-Aronson S, Woodside DG. The growth in the sagittal depth of the bony nasopharynx in relation to some other facial variables. Trans Eur Orthod Soc 1977;69-83.

11. Chang HP. Assessment of anteroposterior jaw relationship.Am J Orthod Dentofac Orthop 1987;92:117-22.

12. Ceylan I, Oktay H. A study on the pharyngeal size in different skeletal patterns. Am J Orthod Dentofacial Orthop.1995;108:69-75.

13. De Freitas MR, Alcazar NM, Janson G, et al. Upper and lower pharyngeal airways in subjects with Class I and ClassII malocclusions and different growth patterns. Am J Orthod Dentofacial Orthop. 2006;130:742-5.

14. Tweed $\mathrm{CH}$. The Frankfort-Mandibular Incisor Angle (FMIA) In Orthodontic Diagnosis, Treatment Planning and Prognosis. The Angle Orthodontist 1954: 24(3):121-69.
15. King EW. A roentgenographic study of pharyngeal growth, Angle Orthod, 1952: 22:23-7.

16. Handelman CS, Osborne G: growth of the nasopharynx and adenoid development from one to eighteen years, Angle Orthod , 1976:46:243-59.

17. Scott JH. Craniofacial regions: a contribution to the study of facial growth, Dent pract Dent Rec, 1955: 5:208-14.

18. Hou HM, Ha"gg U, Sam K, Rabie AB, Wong RW, Lam B, Ip MS. Dentofacial characteristics of Chinese obstructive sleep apnea patients in relation to obesity and severity. Angle Orthod. 2006;76:962-9. 19. De Freitas MR, Alcazar NM, Janson G, de Freitas KM, Henriques JF.Upper and lower pharyngeal airways in subjects with Class I and Class II malocclusions and different growth patterns.Am J Orthod Dentofacial Orthop 2006; 130:742-5.

20. Zhong Z, Tang Z, Gao X, Zeng X-L. A Comparison Study of Upper Airway among Different Skeletal Craniofacial Patterns in Nonsnoring Chinese Children. Angle Orthod. 2010;80:267-74.

21. Memom S, Fida M, Shaikh A. Comparision of different craniofacial patterns with pharyngeal widths. Journal of the college of Physicians and Surgeons Pakistan; 22(5)302-6.

22. Liu Y, Lowe AA, Zeng X, Fu M, Fleetham JA. Cephalometric comparisons between Chinese and Caucasian patients with obstructive sleep apnea. Am J Orthod Dentofacial Orthop.2000;117:479-85.

23. Bosma JF. Maturation of function of the oral and pharyngeal region. Am J Orthod. 1963;49:94-104.

24. McNamara JA. Influence of respiratory pattern on craniofacial growth. Angle Orthod 1981;51:269300.

25. Solow B, Siersbzek-Nielsen S, Greve E. Airway adequacy,head posture, and craniofacial morphology. Am J Orthod. 1984;86:214-23.

26. Kerr WJS. The nasopharynx, face height, and overbite.Angle Orthod 1985;55:31-61.

27. Aboudara C, Nielsen IB, Huang JC, Maki K, Miller AJ, Hatcher D. Comparison of airway space with conventional lateral headfilms and 3-dimensional reconstruction from cone-beam computed tomography. Am J Orthod Dentofacial Orthop 2009; 135:468-79. 
Source of support: Nil, Conflict of interest: None declared

Cite this article as:

Gutpa H, Dua VS, Khanna M. A Cephalometric Comparative Study for Upper Airway

Dimensions in Different Craniofacial Growth Patterns . Int Healthcare Res J 2018;2(6):150-156. doi: 10.26440/IHRJ/02_05/200

\section{AUTHOR AFFILIATIONS:}

1. Senior Lecturer, Department Of Orthodontics and Dentofacial Orthopedics, Kalka Dental College and Hospital, Meerut, UP.

2. Director Principal, National Dental College and Hospital, Dera Bassi, Punjab

3. Reader, Department Of Orthodontics and Dentofacial Orthopedics, MM College of Dental Sciences and Research, Mullana, Haryana

\section{${ }^{*}$ Corresponding Author:}

\section{Dr. Himali Gupta,}

Dept. Of orthodontics

Kalka Dental College and Hospital

Meerut, UP
For article enquiry/author contact details, e-mail at: manuscriptenquiry.ihrj@gmail.com

\section{LEGENDS}

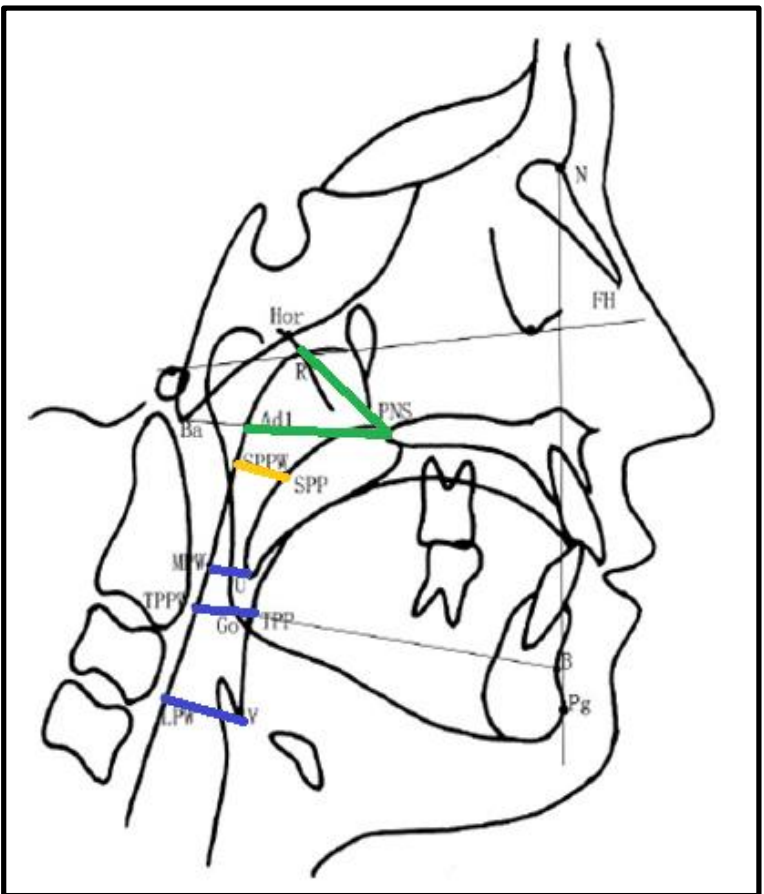

Table 1. Cephalometric Measurements. 


\begin{tabular}{|c|c|c|c|}
\hline Group & $\begin{array}{l}\text { Growth } \\
\text { pattern }\end{array}$ & $\begin{array}{c}\text { FH-MP } \\
\text { angle }\end{array}$ & $\begin{array}{c}\text { Jarabaks' } \\
\text { ratio }\end{array}$ \\
\hline I & Vertical & $\begin{array}{c}\text { Larger } \\
\text { than } \\
30.5^{\circ}\end{array}$ & $\begin{array}{c}\text { Less than } \\
62 \%\end{array}$ \\
\hline II & Average & $\begin{array}{c}\text { Between } \\
23.5^{\circ} \text { and } \\
30.5^{\circ}\end{array}$ & $\begin{array}{c}\text { Between } \\
62 \% \text { and } \\
65 \%\end{array}$ \\
\hline III & Horizontal & $\begin{array}{c}\text { Smaller } \\
\text { than } 23.5^{\circ}\end{array}$ & $\begin{array}{c}\text { Larger } \\
\text { than } 65 \%\end{array}$ \\
\hline
\end{tabular}

Table 1. Classification of Groups.

\begin{tabular}{|c|c|}
\hline & THE LANDMARKS \\
\hline Hor & Most inferior point of spheno-occipital synchondrosis \\
\hline $\mathbf{R}$ & Point of intersection of line from Hor to PNS and posterior pharyngeal wall \\
\hline $\mathbf{B a}$ & Lowermost point on anterior margin of foramen magnum \\
\hline Adi & Point of intersection of posterior pharyngeal wall and line Ptm-Ba \\
\hline SPPW & $\begin{array}{l}\text { Point of intersection of line from soft palate center perpendicular to posterior pharyngeal wall and } \\
\text { posterior pharyngeal wall. }\end{array}$ \\
\hline SPP & $\begin{array}{l}\text { Point of intersection of line from soft palate center perpendicular to posterior pharyngeal wall and } \\
\text { posterior margin of soft palate }\end{array}$ \\
\hline $\mathrm{U}$ & The tip of the uvula \\
\hline MPW & Foot point of perpendicular line from point $U$ to posterior pharyngeal wall \\
\hline TPPW & Point of intersection of posterior pharyngeal wall and extension of line B-Go \\
\hline TB & Point of intersection of base of the tongue and extension of line B-Go \\
\hline $\mathbf{V}$ & The most posteroinferior point on the base of the tongue \\
\hline LPW & Foot point of perpendicular line from point $\mathrm{V}$ to posterior pharyngeal wall. \\
\hline
\end{tabular}

\begin{tabular}{|c|c|c|c|}
\hline \multicolumn{2}{|r|}{ SOFT TISSUE PARAMETERS } & \multicolumn{2}{|c|}{ HARD TISSUE PARAMETERS } \\
\hline \multicolumn{2}{|r|}{ The upper airway dimensions } & \multicolumn{2}{|c|}{ Craniomaxillary complex } \\
\hline PNS-R & Distance between PNS and R & S-N (mm) & Distance between S and N \\
\hline PNS-Adı & Distance between PNS and Adı & ANS-PNS (mm) & Distance between ANS and PNS \\
\hline SPP-SPPW & Distance between SPP and SPPW & PNS-Ba (mm) & Distance between PNS and Ba \\
\hline U-MPW & Distance between U and MPW & & \\
\hline TB-TPPW & Distance between TB and TPPW & \multicolumn{2}{|c|}{ Mandibular size and position } \\
\hline U-MPW & Distance between U and MPW & $\operatorname{Ar}-\mathrm{Gn}(\mathrm{mm})$ & Distance between Ar and Gn \\
\hline TB-TPPW & Distance between TB and TPPW & Go-Gn (mm) & Distance between Go and Gn \\
\hline V-LPW & Distance between V and LPW & FH-NP (u) & Angle between FH and NP plane \\
\hline
\end{tabular}

Table 1. Cephalometric Landmarks and Parameters 


\begin{tabular}{|c|c|c|c|c|c|c|c|}
\hline & ARAMETERS & PNS-R & PNS-Adı & SPP-SPPW & U-MPW & TB-TPPW & V-LPW \\
\hline \multirow{4}{*}{ MEAN } & Horizontal & 20.85 & 22.7 & 10.65 & 11.05 & 11.3 & $15 \cdot 55$ \\
\hline & Vertical & 17.6 & 22.95 & 10.65 & 10.8 & 11.4 & $14 \cdot 5$ \\
\hline & Average & 23.65 & 26.55 & 13.55 & 13.8 & 13.95 & 18.35 \\
\hline & p value & .000 & .051 & .016 & .017 & .023 & .007 \\
\hline \multirow{3}{*}{ H vs A } & Mean Difference & 2.800 & 3.850 & 2.90 & 2.750 & 2.650 & 2.80 \\
\hline & Standard Error & 1.399 & 1.721 & 1.122 & 1.128 & 1.060 & 1.209 \\
\hline & p value & .050 & .029 & .012 & .018 & .015 & .024 \\
\hline \multirow{3}{*}{ V vs H } & Mean Difference & 3.25 & .250 & o & .250 & 1.0 & 1.050 \\
\hline & Standard Error & 1.399 & 1.721 & 1.122 & 1.128 & 1.060 & 1.209 \\
\hline & p value & .024 & .885 & 1.00 & .825 & .925 & .389 \\
\hline \multirow{3}{*}{ A vs $\mathbf{V}$} & Mean Difference & 6.050 & 3.600 & 2.90 & 3.00 & 2.550 & 3.850 \\
\hline & Standard Error & 1.399 & 1.721 & 1.122 & 1.128 & 1.060 & 1.209 \\
\hline & p value & .000 & .041 & .012 & .010 & .019 & .002 \\
\hline
\end{tabular}

Table 3. Cephalometric comparison of normodivergent, hypodivergent and hyperdivergent groups. $(* \mathrm{H}=$ Horizontal, $\mathrm{V}=$ Vertical and $\mathrm{A}=$ Average)

\begin{tabular}{|c|c|c|c|c|c|c|c|c|c|c|}
\hline Parameter & & Mean & $\begin{array}{c}\text { Std. } \\
\text { Deviation }\end{array}$ & $\begin{array}{c}\text { Std. } \\
\text { error }\end{array}$ & Parameter & \multicolumn{3}{c|}{ Mean } & $\begin{array}{c}\text { Std. } \\
\text { Deviation }\end{array}$ & $\begin{array}{c}\text { Std. } \\
\text { error }\end{array}$ \\
\hline \multirow{2}{*}{ AR-GN } & H & 108.85 & 5.967 & 1.334 & S-N & H & 71.15 & 16.617 & 3.715 \\
& V & 103.90 & 6.299 & 1.408 & & V & 73.05 & 3.068 & .686 \\
& A & 108.00 & 9.308 & 2.081 & & A & 73.20 & 3.955 & .884 \\
\hline \multirow{2}{*}{ GO-GN } & H & 77.70 & 6.814 & 1.524 & PNS-BA & H & 49.45 & 3.203 & .716 \\
& V & 72.20 & 6.379 & 1.426 & & V & 45.85 & 4.557 & 1.019 \\
\hline & A & 74.45 & 4.707 & 1.053 & & A & 51.50 & 3.103 & .694 \\
\hline \multirow{2}{*}{ FH-NP } & H & 80.10 & 3.275 & .732 & ANS-PNS & H & 58.15 & 4.158 & .929 \\
& V & 75.00 & 4.554 & 1.018 & & V & 55.75 & 4.621 & 1.033 \\
& A & 76.95 & 4.058 & .907 & & A & 55.50 & 6.278 & 1.403 \\
\hline
\end{tabular}

Table 4. Cephalometric Measurements of the Craniomaxillary Complex, and

Mandible Size and Position in Different Growth Pattern ( $* \mathrm{H}=$ Horizontal, V= Vertical and A= Average)

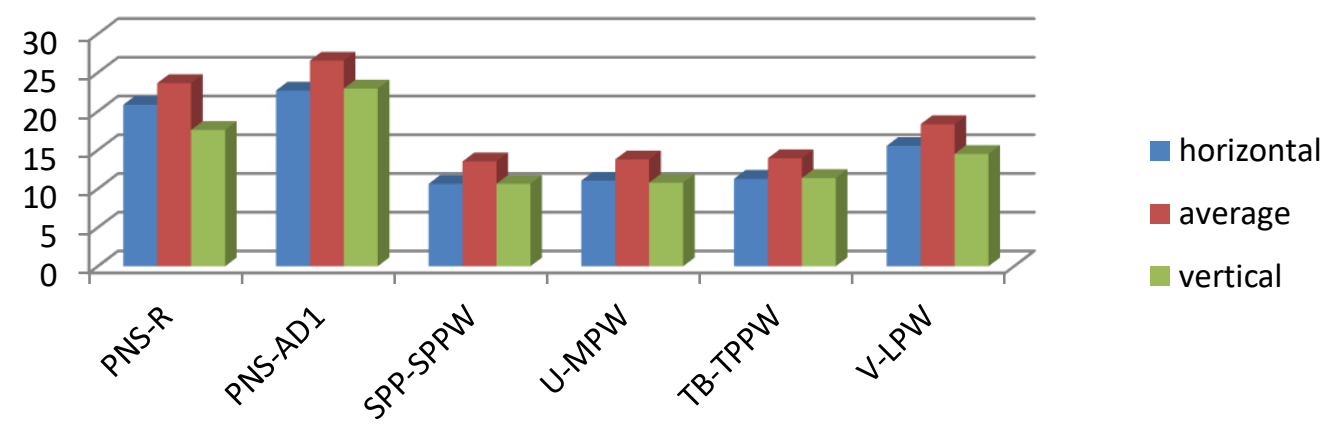

Figure 2. Histogram Plots Showing Comparison Of Different Growth Pattern Groups At Different Soft Tissue Dimension Of Upper Airway. 